\title{
EL DAÑO AMBIENTAL Y LOS DERECHOS DE LA PERSONA
}

\author{
ANTONIO CABANILLAS SÁNCHEZ \\ Catedrático de Derecho Civil \\ Universidad de Alicante
}

A diferencia de lo que acontece en Alemania e Italia, carecemos de una ley que discipline la responsabilidad civil por daños ambientales, aunque nuestra Constitución la contempla, al establecer el art. 45 que «todos tienen derecho a disfrutar de un medio ambiente adecuado para el desarrollo de la persona, y que la violación de lo dispuesto en el apartado 2 (utilización racional de todos los recursos naturales, con el fin de proteger y mejorar la calidad de vida) da lugar a la obligación de reparar el daño causado», utilizándose casi los mismos términos que aparecen en el art. 1902 del Código Civil.

Existe un Anteproyecto de Ley del medio ambiente de Euskadi (1994), que trata de hacer efectivo el principio «quien contamina, paga», como afirma la Memoria que lo presenta. El art. 65 se expresa de la siguiente manera: «Responsabilidad civil. Con independencia de las sanciones la Administración debe imponer al infractor las obligaciones de restaurar el medio ambiente alterado y de indemnizar los daños y perjuicios causados».

A nivel de Derecho comunitario, tampoco existe una Directiva que contemple la reparación del daño ambiental, aunque sí una propuesta modificada de Directiva relativa a la responsabilidad civil por los daños y perjuicios causados al medio ambiente por los residuos (COM núm. 219, de 27 de junio de 1991). Además, es muy importante el Libro Verde sobre reparación del daño ecológico de la Comisión de las Comunidades Europeas (COM núm. 47, de 14 de mayo de 1993), ya que señala los problemas que plantea la responsabilidad civil por daños al medio ambiente y el camino más adecuado para solucionarlos.

Hay que subrayar que España no ha ratificado todavía el Convenio del Consejo de Europa sobre la responsabilidad civil por los daños ocasionados por actividades peligrosas para el medio ambiente, aprobado en Lugano el 8 de marzo de 1993 y abierto a la firma a partir del 21 de junio de 1993.

1 Conferencia pronunciada en el II Congreso Nacional de Derecho Ambiental y en el Ciclo de Conferencias sobre las fronteras de la responsabilidad civil en el siglo XXI, organizado por el Ilustre Colegio de Abogados de Madrid. 
Este panorama evidencia las grandes dificultades que existen para perfilar el significado del daño ambiental y las consecuencias jurídicas que derivan del mismo.

Parece necesario que nuestro legislador elabore una ley que regule adecuadamente la responsabilidad civil por daños ambientales, siguiendo las directrices del Derecho comunitario europeo. La Declaración sobre el medio ambiente y el desarrollo sostenible, fruto de la Conferencia de Naciones Unidas que tuvo lugar en Río de Janeiro del 3 al 14 de junio de 1992, establece que los Estados deben desarrollar la legislación nacional relativa a la responsabilidad y a la indemnización respecto a las víctimas de la contaminación u otros daños ambientales (principio 13). El Ministerio de Medio Ambiente español ha manifestado su propósito de elaborar durante la presente legislatura un Proyecto de Ley sobre responsabilidad civil por daños al medio ambiente. ${ }^{2}$

El Libro Verde sobre reparación del daño ecológico se refiere a las grandes catástrofes ocurridas en la Comunidad Europea, evocando los nombres Seveso, AmocoCádiz, Sandoz, La Coruña o Braer. Son accidentes que provocaron la indignación general y pusieron dramáticamente de manifiesto la necesidad de sanear y restaurar los medios tras un daño ecológico. No obstante, los daños consecuencia de accidentes sólo constituyen una pequeña parte de los daños ecológicos que se producen hoy en día en la Comunidad. Las emisiones de instalaciones industriales y de vehículos de motor contaminan la atmósfera y provocan la muerte de los bosques. Las aguas residuales municipales y agrarias peligrosas depositadas en el pasado contaminan el suelo. Los daños ocasionados por estas actividades, que no constituyen accidentes en sí, son menos espectaculares, pero, en contrapartida, son más frecuentes y no por ello menos necesitados de medidas de reparación.

El Libro Verde sobre reparación del daño ecológico considera fundamental contar con una definición jurídica de daño al medio ambiente, pues ella va a regir el proceso de determinación del tipo y campo de aplicación de las correspondientes medidas de reparación y, consiguientemente, los costes que pueden llegar a recuperarse por la vía de la responsabilidad civil. A pesar de ello, sigue sin haber acuerdo acerca del objeto del daño ecológico, el grado a partir del cual un impacto puede considerarse tal daño y quién tiene derecho a decidir sobre estos aspectos.

La configuración del daño ambiental depende, lógicamente, de la noción que se adopte sobre el medio ambiente, y en este punto no hay concordia, porque hay opiniones que se inclinan por considerar que sólo deberían incluirse en este concepto la vida animal y vegetal y otros componentes de la naturaleza, así como las relaciones entre los mismos, mientras que hay otras opiniones favorables a la inclusión de obje-

2 Sobre el Anteproyecto de Ley de responsabilidad civil por daños al medio ambiente, véase DÍEZ-PICAZO GIMÉNEZ, «¿Es oportuno elaborar una Ley de responsabilidad civil medioambiental?», en La Ley, 1998, núms. 4472 y 4473; POVEDA GÓMEZ, «La responsabilidad civil derivada de actividades con incidencia ambiental. Líneas generales del Proyecto presentado a las Comunidades Autónomas en la conferencia sectorial de medio ambiente», RADAE, 1997, núm. 1, págs. 85 y ss. 
tos de origen humano, si son importantes para el patrimonio cultural de un pueblo. En el Convenio del Consejo de Europa sobre responsabilidad civil por daños ocasionados por actividades peligrosas para el medio ambiente, la acepción de medio ambiente es bastante amplia: incluye recursos naturales abióticos y bióticos, tales como el aire, el agua, el suelo, la fauna y la flora y la interacción de los mismos factores, los bienes que componen el patrimonio cultural y los aspectos característicos del paisaje (art. 2 (10).

El criterio para determinar el grado de impacto a partir del cual existe un daño ambiental es establecido por la propuesta modificada de Directiva relativa a la responsabilidad civil por daños y perjuicios causados al medio ambiente por los residuos, al definir el «deterioro ambiental» como cualquier degradación física, química o biológica importante del medio ambiente, siempre que no se considere daño a un bien (art. 2 d).

Para el Convenio del Consejo de Europa sobre responsabilidad civil por los daños ocasionados por actividades peligrosas para el medio ambiente, el daño significa toda pérdida o daño que resulte de la alteración del medio ambiente (art. $2.7 \mathrm{c}$ ). Sin embargo, el explotador no es responsable, en virtud del presente Convenio, si prueba que el daño resulta de una contaminación de un nivel tolerable, teniendo en cuenta las circunstancias locales pertinentes (art. $8 \mathrm{~d}$ ).

La Ley alemana sobre responsabilidad medioambiental de 1 de diciembre de $1990^{3}$ establece que un daño por influjo medioambiental existe si es causado por sustancias, vibraciones, olores, presiones, rayos, gases, vapores, calores u otros fenómenos que se han propagado por el suelo, el aire o las aguas (art. 3. 1).

Si la instalación se explotaba de conformidad con las disposiciones vigentes (art. 6. 2. 2) se excluye el deber de indemnizar los daños en las cosas, si las mismas se dañan de forma insignificante o en una medida tolerable de acuerdo con las condiciones del lugar (art. 5).

A pesar de su título, esta Ley protege sólo de forma mediata al medio ambiente, ya que su objeto es reparar los daños causados a las personas (muerte o lesiones en el cuerpo o la salud) o a las cosas por influjos al medio ambiente, procedentes de determinadas instalaciones (art. 1. 1).

Sólo el que es directamente lesionado en uno de los bienes jurídicos protegidos puede demandar la indemnización del daño sufrido. ${ }^{4}$

3 Una excelente traducción de esta Ley por CAÑIZARES y RODRÍGUEZ TAPIA, «La nueva regulación alemana en materia de responsabilidad por daños causados al medio ambiente», ADC, 1994, págs. 209 y ss.

4 LANDSBERG y LÜLLING, «Umwelthaftungsrecht», I, Umwelthaftungsgesetz, Köln, 1991, págs. 30 y ss.; SCHMIDT-SALZER, Kommentar zum Umwelthaftungsrecht, München, 1992, págs. 400, 417, 842 y 843; SALJE, Umwelthaftungsgesetz. Komentar, München, 1993, págs. 100 y ss.; MEDICUS, Schuldrecht, II, Besonderer Teil, München, 1993, pág. 790; Hager, «Das neue Umwelthaftungsgesetz», NJW, 1991, págs. 133 y 134. 
La Ley italiana de 8 de julio de 1986, de constitución del Ministerio del Medio Ambiente, contiene -pesar de su objetivo primario- reglas sustantivas en materia de responsabilidad por daños ambientales, estableciendo que el daño surge cuando se altera, deteriora o destruye en todo o en parte el medio ambiente. Sin embargo, la responsabilidad del autor del daño, que obliga al resarcimiento respecto al Estado, se hace depender de que exista un hecho doloso o culposo que implique la violación de las disposiciones legales o de las resoluciones adoptadas con fundamento en la ley (art. 18).

Tanto en nuestro Derecho como en el francés no es disciplinado legalmente el daño ambiental, lo cual hace extraordinariamente difícil su configuración.

Caballero ${ }^{5}$ destaca la indiferencia existente en el Derecho francés hacia el daño ecológico.

Consciente de la amplitud y gravedad de la indiferencia del Derecho positivo, un sector de la doctrina se ha esforzado para remediarla proponiendo que se reconozcan nuevos derechos destinados a extender los medios para luchar contra las agresiones al medio ambiente.

En su tesis sobre la reparación del daño ecológico, Girod ${ }^{6}$ distingue entre dos clases de daños ecológicos: el daño ecológico en sentido amplio, es decir, todo lo que degrada el medio ambiente, y el daño ecológico en sentido estricto, es decir, la degradación de los elementos naturales (aguas, aire, nivel sonoro).

Siguiendo esta evolución, Caballero ${ }^{7}$ preconiza el reconocimiento de un daño directo al medio ambiente, y da la siguiente definición: es daño ecológico todo daño causado directamente al medio considerado en cuanto tal independientemente de sus repercusiones sobre las personas y sobre los bienes.

Si se atiende a los daños causados al medio ambiente en cuanto tal, debe eliminarse una masa considerable de daños causados a las personas y a los bienes por nuisances.

Admitir la definición positiva de los daños ecológicos, es admitir que al lado del daño material, corporal o moral causado al hombre o a sus bienes, existe una nueva categoría de daños causados al medio ambiente. Sin duda una semejante categoría de daño es desconocida por el Derecho positivo. No es, sin embargo, una razón para rechazar sistemáticamente la idea. La originalidad del daño ecológico, la complejidad de los problemas del medio ambiente que suscita su desconocimiento, merecen que los juristas lleven a cabo un esfuerzo de imaginación.

Prieur ${ }^{8}$ prefiere introducir una distinción entre los daños por contaminación, que serían sufridos por patrimonios identificables y particulares, y los daños ecológicos

5 CABALLERO, Essai sur la notion juridique de nuisance, París, 1981, págs. 287 y ss.

6 GIROD, La réparation du dommage écologique, París, 1974, pág. 19.

7 CABALLERO, op. cit., págs. 293 y ss.

8 PRIEUR, Droit de l'environnement, París, 1991, págs. 293 y ss. 
propiamente dichos, sufridos por el medio natural en sus elementos inapropiados e inapropiables y que afectan al equilibrio ecológico en tanto que patrimonio colectivo. A menudo un mismo accidente entraña dos tipos de daños.

Este autor evidencia la especificidad del daño ecológico. Los fenómenos que afectan al medio ambiente se caracterizan muy a menudo por su gran complejidad. Es preciso sobre todo poner de relieve los elementos siguientes que se encuentran raramente en los daños no ecológicos: las consecuencias dañosas de una agresión al medio ambiente son irreversibles (no se reconstituye un biotopo o una especie en peligro de extinción), están a menudo vinculadas al progreso tecnológico; la contaminación tiene efectos acumulativos y sinérgicos que hacen que las contaminaciones se adicionen y se acumulen entre ellas; la acumulación de nuisances a lo largo de la cadena alimentaria puede tener consecuencias catastróficas (enfermedad de Minamata en Japón); los efectos de los daños ecológicos pueden manifestarse más allá de la vecindad (efecto río abajo de una contaminación a larga distancia de SO 2); son daños colectivos por sus causas (pluralidad de autores, desarrollo industrial, concentración urbana) y sus efectos (costes sociales); son daños difusos en su manifestación (aire, radioactividad, contaminación de las aguas) y en el establecimiento de la relación de causalidad; son repercutidos en la medida en que implican agresiones principalmente a un elemento natural y por rebote a los derechos individuales.

Como subrayan Litmann-Martin y Lambrechts 9 , la mayoría de los autores reservan el calificativo de «ecológico» para definir aquel daño que afecta al conjunto del medio natural o alguno de sus componentes considerando como patrimonio colectivo independientemente de sus repercusiones sobre las personas y los bienes.

Se habla de daño ecológico puro, ajeno a cualquier connotación personal, patrimonial o económica (Martin).

La situación existente en nuestro Derecho es semejante a la francesa. No existe una ley que contemple específicamente el daño ambiental y la responsabilidad que deriva del mismo.

No obstante, del art. 45 de nuestra Constitución se infiere que el daño ambiental es el resultado de la lesión del derecho que «todos» tienen a disfrutar de un medio ambiente adecuado para el desarrollo de la persona.

El daño ambiental implica un acto antijurídico, lesivo del derecho al medio ambiente, como subraya Postiglione 10.

La emisión de gases, polvos y humos, así como los vertidos industriales, constituye la causa más frecuente de daños ambientales.

9 LITMANN-MARTIN y LAMBRECHTS, «La spécificité du dommage écologique», en Le dommage écologique en droit interne, communautaire et comparé, bajo la dirección de Martin, París, 1992, págs. 45 y ss.

10 POSTIGLIONE, Il diritto all'ambiente, Napoli, 1982, 1982, pág. 77. 
El ámbito del daño ambiental está determinado, lógicamente, por el significado que se otorgue al medio ambiente, lo cual es señalado por el Libro Verde sobre reparación del daño ecológico, como hemos visto.

El art. 45 de nuestra Constitución aboga por una concepción amplia del medio ambiente, aunque no omnicomprensiva. El elemento nuclear del concepto constitucional de medio ambiente no es otro que los recursos naturales. Por ello, como puntualiza Díez-Picazo "1, el medio ambiente está constituido por el conjunto de elementos naturales que determinan las características de un lugar, tales como el aire, el agua, el suelo, la flora, la fauna, el paisaje y otras que contribuyen al goce de los bienes de la naturaleza, como el silencio y la tranquilidad. 12

En nuestro Derecho, no existe una limitación como la que establece la Ley italiana para la relevancia del daño ambiental. Según el art. 18.1 de esta Ley, el hecho productor del daño sólo es considerado injusto en el caso de violación de disposiciones legales o de resoluciones adoptadas con base en la ley. De esta manera se establece una tipicidad del ilícito ambiental, que no sorprende a Visintini ${ }^{13}$, porque se trata de una norma que considera que el Estado es la víctima del daño. Por ello, no todo daño al medio ambiente es considerado resarcible, sino sólo el «injusto», que es aquél que deriva de la violación de disposiciones legales o de resoluciones adoptadas con base en la ley. La doctrina italiana ${ }^{14}$ destaca que el daño ambiental tiene naturaleza pública, basándose en el texto del art. 18.1. El daño se causa al Estado y por eso sólo él (o los entes territoriales) está legitimado para interponer una demanda de resarcimiento. El daño ambiental es el resultado de la lesión de un bien inmaterial con reflejos patrimoniales y tiene naturaleza pública.

Perlingieri 15 afirma que el cuadro trazado por el legislador italiano de 1986 deja insatisfechos a los privatistas, cuando reduce el daño ambiental a la exclusiva agre-

11 DÍEZ-PICAZO, Fundamentos de Derecho civil patrimonial, III, Madrid, 1995, pág. 203.

12 Sobre las diversas concepciones para caracterizar al medio ambiente como objeto del Derecho, MARTÍN MATEO, Tratado de Derecho ambiental, I, Madrid 1991, págs. 80 y ss; López Ramón, «El derecho ambiental como derecho de la función pública de protección de los recursos naturales», RDA, $1994, \mathrm{n}^{\circ} 13$, págs. 38 y ss.

13 VISINTINI, «Convegno su il danno ambientale con riferimento alla responsabilità civile», bajo la dirección de Perlingieri, Napoli, 1991, pág. 53.

14 ALPA, «La natura giuridica del danno ambientale», en Il danno ambientale con riferimento alla responsabilità civile, bajo la dirección de Perlingieri, Napoli, 1991, págs. 107 y ss.; BARBIERA, «Qualificazione del danno ambientale nella sistematica general del danno», en Il danno ambientale con riferimento alla responsabilita civile, bajo la dirección de Perlingieri, Napoli, 1991, págs. 114 y ss.; GIAMPIETRO, «Azione di danno dello Stato e degli enti territoriali. Poteri di intervento in giudizio delle associazioni ambientali», bajo la dirección de Perlingieri, Napoli, 1991, pág. 171.

15 PERLINGIERI, «Presentazione» a Il danno ambientale con riferimento a la responsabilità civile, bajo la dirección de Perlingieri, Napoli, 1991, pág. 5. 
sión a un bien público inmaterial insusceptible de apropiación, perteneciente al Estado-persona, que monopoliza la acción resarcitoria.

El hecho de que sólo se legitime al Estado ha determinado que el art. 18 haya tenido una escasa aplicación práctica en Italia. Por ello, como subraya Comporti ${ }^{16}$, el art. 18 constituye en ciertos aspectos un retroceso respecto a los principios mayoritariamente innovadores con anterioridad afirmados.

En la misma línea, Giampietro ${ }^{17}$ apunta que el Ministerio no ha dado hasta este momento prueba de dinamismo, ni en sede civil, ni, en algunas ocasiones, en sede penal.

Tampoco son numerosas las iniciativas procesales de las regiones y/o los entes locales. Esto tiene una precisa explicación en el hecho de que las regiones y los entes locales están implicados, en diverso modo, en los hechos de contaminación ambiental por defecto de vigilancia, situaciones de inercia organizativa, falta de personal y de estructuras técnicas apropiadas, incapacidad de gobierno del territorio, etcétera.

De esta manera se corre el riesgo de que el daño ambiental sea de hecho considerado jurídicamente irrelevante.

En nuestra doctrina, Jesús Jordano Fraga 18 observa con toda razón que el planteamiento de la Ley italiana no puede ser más erróneo, siendo sorprendente que se haya desconocido la elaboración jurisprudencial (italiana) sobre el derecho al medio ambiente. $\mathrm{Y}$ es que el ejercicio de resarcimiento se ha desconectado del derecho al medio ambiente.

Afortunadamente en España no existe una ley como la italiana, que conciba de esta manera al daño ambiental. Cabe sostener por ello que este tipo de daño puede tener reflejos privatistas, teniendo en cuenta el derecho a un medio ambiente adecuado para el desarrollo de la persona, reconocido en el art. 45 de nuestra Constitución. Por este motivo, no es preciso limitar la legitimación para exigir responsabilidad por daños ambientales al Estado, sino que las asociaciones y grupos afectados pueden invocar ante los Tribunales el derecho de «todos» a un medio ambiente adecuado para el desarrollo de la persona. El art. 24 de la Constitución, en interpretación concorde con el art. 9. 2 de la misma, permite establecer la efectividad del derecho a la jurisdicción que incluya en el concepto «sus derechos o intereses legítimos» la tutela de los intereses colectivos o difusos. La Ley Orgánica del Poder Judicial, de 1 de junio de 1985, confirma esta interpretación, al disponer el art. 7. 3 que «los Juzgados y Tribunales protegerán los derechos e intereses legítimos, tanto individuales como colectivos, sin que en ningún caso pueda producirse indefensión.

16 COMPORTI, «Tutela dell'ambiente e tutela della salute», RGA, 1990-2, págs. 208 y 209.

17 GIAMPIETRO, «La proposta di direttiva comunitaria sui danni all'ambiente causati da rifiuti in relazione alla disciplina generale dell'art. 18 della legge núm. 349/1986», RGA, 1991-1, págs. 49 y 50 .

18 Jesús JORDANO FRAGA, La protección del derecho a un medio ambiente adecuado, Barcelona, 1995, pág. 382. 
Para la defensa de estos últimos se reconocerá la legitimación de las corporaciones, asociaciones y grupos que resultan afectados o que estén legalmente habilitados para su defensa y promoción».

Así pues, se reconoce legalmente la necesidad de legitimaciones amplias que responden a la problemática de los denominados intereses difusos o colectivos. 19

Asegurar el acceso a la justicia de los grupos de intereses difusos o colectivos para la defensa del medio ambiente, parece una tarea inexcusable, que encuentra apoyo en los arts. 45 y 24 de nuestra Constitución y en el art. 7.3 de la Ley Orgánica del Poder Judicial. En el marco de la responsabilidad civil por daños ambientales, parece oportuno reconocer a las asociaciones ecologistas y grupos afectados capacidad procesal y legitimación para actuar ante cualquier jurisdicción, afirmando la eficacia erga omnes de las sentencias en todo lo que no perjudique a los afectados.

Otro argumento para sustentar la apuntada legitimación se encuentra en la relación existente entre el medio ambiente y la salud (arts. 43 y 45 de la Constitución) y, en general, los derechos de la personalidad, que gozan de una específica tutela civil.

La conexión entre el derecho a disfrutar de un medio ambiente salubre, al que se refiere la sentencia del Tribunal de Casación italiano de 6 de octubre de 1979 20, y los derechos de la personalidad se advierte claramente en la Ley General de Sanidad de 25 de abril de 1986, al aludir a la sanidad ambiental (art. 19), y en el propio texto del art. 45.1 de nuestra Constitución, al reconocer el derecho de «todos» a disfrutar de un medio ambiente adecuado para el desarrollo de la persona ${ }^{21}$.

La sentencia del Tribunal Europeo de Derechos Humanos de 9 de diciembre de 1994, dictada en el asunto López Ostra contra España, manifiesta que los atentados graves al medio ambiente pueden afectar al bienestar de una persona hasta el punto de privarla de la tranquilidad de su domicilio, lesionando su vida privada y familiar, así como su salud. Se considera aplicable el art. 8 del Convenio Europeo para la Protección de los Derechos Humanos y de las Libertades Fundamentales (Roma, 4 de noviembre de 1950; Instrumento de ratificación de 26 de septiembre de 1979).

El citado Tribunal no tuvo ningún inconveniente en estimar la demanda interpuesta por la señora López Ostra en la que alegaba que a consecuencia de inmisiones de olores, ruidos y humos procedentes de una estación depuradora habían sido vulnerados los siguientes derechos fundamentales: el derecho a la integridad física y

19 ALMAGRO y TOMÉ, Instituciones de Derecho procesal. Proceso civil, Madrid, 1994, págs. 239 y 240; GÓMEZ DE LIAÑO, «La legitimación colectiva y el artículo 7 de la Ley Orgánica del Poder Judicial», Justicia, 1986, págs. 555 y ss.; Silguero, La tutela jurisdiccional de los intereses colectivos a través de la legitimación de los grupos, Madrid, 1995, págs. 305 y ss.

20 Giur. it., 1980, I, págs. 463 y ss., y 159 y ss., con notas de PATTI y SALVI.

21 CABANILLAS, La reparación de los daños al medio ambiente, Madrid, 1996, págs. 226 y ss. 
moral y la proscripción de torturas y tratos inhumanos y degradantes y el derecho al respeto a la vida privada y familiar y al domicilio. ${ }^{22}$

Para ser relevante el daño ambiental ha de tener una cierta gravedad. Si el daño es insignificante o tolerable de acuerdo con las condiciones del lugar, no surgirá la responsabilidad, y por tanto, no estaremos en rigor ante un daño ambiental resarcible. Esta es a solución que se infiere, según hemos visto, de la propuesta modificada de Directiva relativa a la responsabilidad civil por los daños y perjuicios causados al medio ambiente por los residuos, del Convenio del Consejo de Europa sobre responsabilidad civil por los daños ocasionados por actividades peligrosas para el medio ambiente y de la Ley alemana sobre responsabilidad medioambiental de 10 de diciembre de 1990, y que es razonable sustentar también en nuestro Derecho en línea con la teoría de la normal tolerancia que, en el marco de las relaciones de vecindad, opera como límite de la responsabilidad por inmisiones, como se infiere de algunos preceptos concretos de nuestro Código civil (arts. $1908-2^{\circ}$ y 7. 2) y de la posición adoptada por nuestra doctrina, en línea con el criterio imperante en el Derecho comparado ${ }^{23}$. La tolerabilidad excluye la ilicitud y no surge, por tanto, la responsabilidad civil por daño ambiental.

El hecho antijurídico puede consistir en una lesión efectiva o en una situación de peligro del medio ambiente.

No puede desconocerse que el medio ambiente resulta comprometido también por la exposición al peligro, ya que implica per se una conducta lesiva. Por esto se afirma, como mecanismo de reparación, la eliminación de la exposición a peligro del medio ambiente. Este mecanismo se fundamenta en los valores jurídicos que requieren una tutela anticipada. ${ }^{24}$

22 Sobre esta importante sentencia, EGEA, «Condiciones medioambientales y derechos fundamentales. Inmisiones perjudiciales que obligan a abandonar el domicilio (a propósito de la Sentencia del TEDH de 9 de diciembre de 1994), DP y C, 1996, nº 9, págs. 323 y ss.; CARRILLO DONAIRE y GALÁN VIOQUE, « ¿Hacia un derecho fundamental a un medio ambiente adecuado?», REDA, 1995, n 86, págs. 271 y ss.; GARCÍA SAN JOSÉ, «Derecho al medio ambiente y respeto a la vida privada familiar», La Ley, 1995, núm. 3896, págs. 1 y ss.

23 CABANILLAS, La reparación de los daños al medio ambiente, cit., págs. 51 y ss., con amplia información doctrinal y jurisprudencial sobre la responsabilidad civil por inmisiones en el marco de las relaciones de vecindad y el criterio de la normal tolerancia, que formulará Jhering, «Zur Lehre von den Beschränkungen des Grundeigentümers im Interesse der Nachbarn», JherJ, IV, 1863, págs. 81 y ss., esp. 113 y ss.

24 POSTIGLIONE, Il diritto all'ambiente, cit., pág. 87; ALBAMONTE, Danni all'ambiente $e$ responsabilità civile, Padova, 1989, págs. 39 y 40. 